\title{
Hastanelerde Maliyet Analizi ve Tıbbi Rehabilitasyon Hizmetlerinde Birim Maliyet Hesaplanması
}

\section{Cost Analysis in Hospitals and Calculation of Unit Costs in Medical Rehabilitation Services}

\author{
Ismail AĞIRBAȘ, Haydar GÖK*, Yasemin AKBULUT, Ömer Rifkı ÖNDER \\ Ankara Üniversitesi Sağlık Bilimleri Fakültesi, Sağıı Kurumları Yöneticiliği, Ankara, Türkiye \\ *Ankara Üniversitesi Tıp Fakültesi, Fiziksel Tıp ve Rehabilitasyon Anabilim Dalı, Ankara, Türkiye
}

\section{Özet}

Amaç: Araştırmanın amacı, üçüncü basamak bir hastanenin Fiziksel Tıp ve Rehablitasyon (FTR) kliniğinde maliyet analizi yaparak verilen tıbbi rehabilitasyon hizmetleri için gerçeğe yakın maliyet rakamlarına ulaşılabileceğini ve maliyet fonksiyonlarının oluşturulabileceğini ortaya koymaktır. Böylece hastane yöneticilerine finansal planlama, performans denetimi ve kalite geliștirme konusunda rehberlik sağlanabilecektir.

Gereç ve Yöntem: Araştırma retrospektif olarak tıbbi, idari, mali ve teknik verilerin incelenmesi ve değerlendirilmesi yoluyla yürütülmüştür. Araştırmanın evrenini üçüncü basamak bir hastanenin FTR kliniğinde 2010 yılı içinde verilen tıbbi hizmetler oluşturmaktadır. Örnekleme yapılmamış olup klinikte ayaktan ve yatarak tedavi gören tüm hastaların fizik tedavi ve rehabilitasyon seansları araştırma kapsamına alınmıştır. Bulgular: Araştırma sonucunda; poliklinik maliyeti $72,02 \mathrm{TL}$, yatan hasta maliyeti $7.825,54 \mathrm{TL}$, hasta günü maliyeti $221,05 \mathrm{TL}$ ve fizik tedavi seans maliyeti 49,38 TL olarak bulunmuştur. Bu maliyetler Sosyal Güvenlik Kurumu'nun hizmet sunucularına yaptığı ödeme rakamlarının üstündedir. Sonuç: Geri ödeme kurumlarının hizmet sunucuları için ödeme rakamlarını belirlerken maliyet analizi sonuçlarını dikkate almasında yarar bulunmaktadır. Türk Fiz Tıp Rehab Derg 2012;58:103-8.

Anahtar Kelimeler: Fizik tedavi ve rehabilitasyon, hastane, maliyet analizi

\section{Summary}

Objective: The aim of this study was to demonstrate that actual cost values of medical rehabilitation services and cost functions could be estimated by using cost analysis in a physical and rehabilitation medicine (PMR) clinic of a thirdlevel hospital. This, in turn, could guide the hospital administrators in their financial planning, performance audit, and quality development issues. Materials and Methods: This is a retrospective study which was conducted by investigating and evaluating the medical, administrative, financial, and technical data. The true population of the study consisted of medical rehabilitation services provided in a PMR clinic of a third-level hospital in 2010. Since sampling was not done, all treatment sessions of outpatients and inpatients done in the PMR unit were included in the study.

Results: After analysis, the cost for an outpatient was found to be 72.02 $\mathrm{TL}$, for an inpatient 7.825.54 TL, for patient day 221.05 TL and for a PMR session $49.38 \mathrm{TL}$. These values were higher than the values paid to medical care providers by the Social Security Institution.

Conclusion: Reimbursement institutions need to take cost analysis data into consideration when determining the rates of repayment for medical care providers. Turk J Phys Med Rehab 2012;58:103-8.

Key Words: Physical medicine and rehabilitation, hospital, cost analysis

\section{Giriş}

Bir ülkenin en önemli kaynağı insandır. Toplumu oluşturan bireylerin ve dolayısıyla toplumun en büyük zenginliği ise sağlığıdır. Bu nedenle sağlık sorunlarını belli düzeyde çözmüş olan ülkelerde genel olarak ekonomik, siyasal ve sosyal yapılar da sağlıklıdır. Birey ve toplum hayatında önemli bir yeri olan sağlık ve sağlık hizmetleri için yapılan harcamalar giderek artmaktadır. Ülkeler Gayri Safi Yurtiçi Hâsılalarının, önemli bir kısmını sağlık harcamaları için kullanmaktadır. Bunun sonucu olarak sağlık hizmetleri maliyeti sürekli olarak gündemde olan önemli konulardan biridir. Kamu ve özel sektör tarafından yürütülen politikalar sağlık hizmetlerini doğrudan etkilemektedir. Bu nedenle sağlık hizmetleriyle ilgili kararların bilimsel kanıtlara dayanması gerekmektedir. 
Toplumlara çeşitli sağlık hizmetleri sunan hastaneler, sağlık sisteminin en önemli kuruluşlarıdır. Tıp bilimi ve teknolojisindeki gelişmelere paralel olarak hastaneler hızla değişmiş, önemleri gittikçe artmış ve sağlık harcamalarının önemli bir bölümünü tüketen sosyoekonomik kuruluşlar haline gelmişlerdir (1). Bu gelişim hastane yönetimin önemini arttırmıştır. Hastane yönetim faaliyetlerinde bilgi temininin önemi büyüktür. Bir konuda alınacak kararların isabeti, o konudaki bilgilerin niteliği, niceliği ve güncelliğine bağlıdır. Maliyet muhasebesi, hastane yöneticilerine hastane hakkında finansal bilgiler sunmayı amaçlayan ve onların sağlıklı kararlar almasına yardımcı olan önemli bir araçtır.

Hastane maliyet muhasebesi; hastane genel muhasebe alt sistemlerinden aldığı finansal bilgileri, hastane işletmesinin hizmet üretim maliyetlerinin belirlenmesi için kendine özgü teknikler ile kaydeden, sınıflayan ve raporlayan bir finansal bilgi sistemidir. Bu sistemin başlıca amaçları, birim maliyetleri saptamak, maliyet kontrolü, planlama ve karar vermeye yardımcı olmaktır $(2,3)$. Hastane maliyet muhasebesi sistemi içerisinde değerlendirilen maliyet verilerinden yararlanarak, gerçekleşen hizmet maliyetlerinin değerlendirmesini yapan ve bu değerlendirmeler sonucunda hastane yöneticilerinin alacakları finansal kararlara ışık tutmaya yardımcı olan çalışmalar da hastane maliyet analizi olarak ifade edilmektedir (2). Hastane maliyet muhasebesi ve hastane maliyet analizleri iç içe olduğu için bir arada değerlendirilmektedir.

Hastane yöneticilerinin, finansal veriler üzerinde etkinlik sağlayabilmeleri için iki önemli maliyet çalışmasını gerçekleştirmeleri gerekmektedir. Bunlardan ilki hastanede yapılan maliyetlerin maliyet merkezlerine dağıtılması ve ikincisi ise bu merkezlerde verilen hizmetlerin birim maliyetlerinin hesaplanmasıdır (4). Bu hesaplamalar ancak ayrıntılı bir maliyet analizi çalışması ile yapılabilir. Maliyet analizi hastanenin hizmet verirken ortaya çıkan maliyetlerin maliyet merkezlerine dağıtılması ve maliyetlerin sebep sonuç ilişkilerinin irdelenmesi sürecidir. Başka bir tanımla maliyet analizi, hastanenin ürettiği hizmetin üretimi sürecinde rol oynayan maliyet merkezlerinde oluşan maliyetlerin, nihai çıktı sunan maliyet merkezlerine mantıklı bir şekilde dağıtılması ve bu maliyetlerin analiz edilmesi sürecidir (5).

Mevcut araştırma, bir üçüncü basamak hastanesi Fiziksel Tıp ve Rehabilitasyon (FTR) kliniğinde yürütülmüştür. FTR uzmanlık alanı kapsamına giren hastalıklar genellikle bireylerin yaşam kalitesini doğrudan etkilemektedir. Dolayısı ile bu hastalıkların teşhis ve tedavi süreci önem arz etmektedir. Tipik olarak bir FTR kliniğine başvuran hastanın poliklinikteki muayenesi ve klinik tedavisi uzun zaman almaktadır. Bunun bir sonucu olarak FTR klinikleri yüksek yatak doluluk oranı ve düşük yatak devir hızı ile hizmet vermektedir. Ayrıca giderlerin içinde, sabit giderlerin oranının oldukça yüksek olduğu iyi bilinen bir gerçektir. Tüm bu özellikler FTR birim maliyetlerinin yüksek çıkmasına neden olmaktadır.

Bu nedenle mevcut çalışma ile, üçüncü basamak bir hastanenin FTR kliniğinde maliyet analizi yapılarak verilen tıbbi rehabilitasyon hizmetleri için gerçeğe yakın maliyet rakamlarına ulaşılabileceğini ve maliyet fonksiyonlarının oluşturulabileceğini ortaya koymak amaçlanmıştır. Böylece hastane yöneticilerine finansal planlama, performans denetimi ve kalite geliştirme konusunda rehberlik sağlanabilecektir.

\section{Gereç ve Yöntem}

Araştırma bir üçüncü basamak hastanesi FTR kliniğinde yürütülmüş ve poliklinik maliyeti, FTR seans maliyeti, yatan hasta ve hasta günü maliyetleri hesaplanarak toplam ve birim maliyet fonksiyonları oluşturulmuştur. Bu yolla, hastane ve sağlık yöneticilerine maliyet muhasebesi, planlama, performans ve kalite geliştirme çalışmalarında katkı sağlanması hedeflenmiştir. Hastanelerde maliyet analizi çalışmalarında altı aşamadan oluşan bir süreç izlenmektedir (6). Bu aşamalar;

1. Çıktıların belirlenmesi

2. Maliyet merkezlerinin tanımlanması

3. Maliyet kalemlerinin belirlenmesi

4. Maliyetlerin maliyet merkezlerine dağıtımı

5. Destek maliyet merkezlerindeki maliyetlerin, yardımcı ve esas maliyet merkezlerine dağıtımı

6. Yardımcı ve esas maliyet merkezlerinin toplam ve birim maliyetlerinin hesaplanarak maliyet fonksiyonlarının oluşturulması şeklindedir.

Maliyet analizinin son aşaması, toplam ve birim maliyet fonksiyonlarının oluşturulmasıdır. Birinci ve üçüncü maliyet dağıtım tablolarından yararlanılarak her bir yardımcı ve esas maliyet merkezi için toplam ve birim maliyet fonksiyonları oluşturulmaktadır. Denklemlerde yer alan sabit ve değişken maliyetler 1 . ve 3 . gider dağıtım tabloları yardımıyla hesaplanmaktadır.

Toplam maliyet fonksiyonu; $\mathrm{TM}=\mathrm{ax}+\mathrm{b}$ şeklindedir. $\mathrm{Bu}$ fonksiyonda; $a$ = Birim Değişken Maliyet, $X=$ Üretim Miktarı, $b=$ Toplam Sabit Maliyet

Birim maliyet fonksiyonu; $\mathrm{BM}=\mathrm{a}+\mathrm{b} / \mathrm{X}$ şeklindedir. $\mathrm{Bu}$ fonksiyonda; $a$ = Birim Değişken Maliyet, $X=$ Üretim Miktarı, $b=$ Toplam Sabit Maliyet

\section{Örnekleme, Verilerin Toplanması ve Değerlendirilmesi}

Üçüncü basamak hastanesi FTR kliniğine ait 2010 mali verileri ile ayakta ve yatarak verilen hizmetler çalışmanın evreni olarak kabul edilmiştir. Örnekleme yapılmamıştır. Veriler, hastanenin tıbbi, idari, mali ve teknik kayıtlarından yararlanılarak toplanmıştır. Çalışmanın yürütüldüğü klinik ve genel hastaneye ait hizmet göstergeleri karşılaştırmalı olarak Tablo 1'de gösterilmiştir. Toplanan veriler ile hesaplanan maliyet rakamları, Sosyal Güvenlik Kurumu (SGK) Sağlık Uygulama Tebliği (SUT) fiyatları ile karşılaştırılarak değerlendirmeler yapılmıştır.

\section{Bulgular}

\section{FTR Kliniğinde Maliyetlerin Dağıtımı}

Öncelikle, FTR kliniği maliyetlerinin dağıtımı yapılmış ve birinci maliyet dağıtım tablosu oluşturulmuştur (Tablo 2). 2010 yılı FTR birinci dağıtım toplam maliyeti 5.347.706,88 TL olarak saptanmıştır. Birinci dağıtım sonunda en büyük payı 3.655.756,83 TL ile yatan hastaların oluşturduğu klinik maliyet merkezi alırken, FTR ünitesi 1.216.053,47 TL ile ikinci sırada yer aldığı ve en düşük maliyet payının ise 565.896,58 TL ile poliklinikte gerçekleştiği saptanmıştır (Tablo 3). Birinci dağıtım sonuçlarına göre personel maliyetlerinin toplam maliyetler içindeki oranı $\% 71,69^{\prime}$ dur. Personel maliyetleri hesaplanırken personelin hem poliklinikte hem de klinikte çalışması dikkate alınmıştır. Daha önce yapılmış maliyet 
analizi çalışmalarında zaman analizi kapsamında çalışan personelin maliyetinin \%20'sinin polikliniğe yansıtıldığı tespit edilmiştir $(7,8)$. Mevcut çalışmada da bu oran kullanılmıştır. İlaç ve tıbbi malzeme maliyetlerinin toplam maliyetler içindeki oranı \%4,81 ve genel üretim maliyetlerinin toplam maliyetler içindeki oranı \%23,5 olarak hesaplanmıştır (Tablo 2).

Genel üretim maliyetleri; elektrik, su, doğalgaz, haberleşme, tamir, bakım-onarım, temizlik, tıbbi atık, tıbbi gaz, demirbaş ve bina amortismanı, tekstil, kırtasiye, Atom Enerjisi Kurumu ve yemek maliyetlerini kapsamaktadır.

İkinci aşamada yardımcı üretim maliyet merkezleri ile yardımcı hizmet ve yönetim maliyet merkezlerinde toplanan maliyetler, bu maliyet yerlerinden yararlanan maliyet merkezlerine aralarındaki hizmet ilişkileri dikkate alınarak dağıtılmış ve ikinci dağıtım tablosu oluşturulmuştur. İkinci dağıtım sonucunda toplam maliyet 5.876.071,31 TL bulunmuştur. Bu maliyetin 3.945.065,30 TL'si klinik maliyet yerinde, 1.224.587,45 TL'si FTR tedavi merkezinde ve 706.418,57 TL'si poliklinik maliyet yerinde gerçekleşmiştir.

Üçüncü aşamada yardımcı üretim maliyet merkezleri başlığı altında toplanan, laboratuvarlar (örn. EKO, EKG lab), tıbbi kurullar, radyoloji, diyet ünitesi, eczane, kan merkezi, klinik nutrisyon ve doğrudan yüklenmesi mümkün olmayan maliyetler uygun dağıtım anahtarları kullanılarak, poliklinik, klinik ve FTR tedavi merkezine maliyet dağıtımı yapılarak üçüncü dağıtım gerçekleştirilmiştir. Üçüncü dağıtım sonucunda toplam maliyet, 7.128.589,76 TL olmuştur. Bu maliyetin 4.507.513,31 TL'sinin klinik maliyet yerine, 1.319.582,82 TL'sinin FTR tedavi merkezine

Tablo 1. Hastane ve Fiziksel Tıp ve Rehabilitasyon Kliniğine ait hizmet göstergeleri.

\begin{tabular}{|l|c|c|}
\hline Hizmet & Hastane Geneli & FTR Kliniği \\
\hline Poliklinik sayısı & 860.480 & 18.070 \\
\hline Yatan hasta sayısı & 53.217 & 576 \\
\hline Hasta yatııııma oranı (\%) & 6,2 & 3,2 \\
\hline Hasta günü sayısı & 467.139 & 20.391 \\
\hline Hasta yatağı sayısı & 1.843 & 77 \\
\hline Ortalama yatış süresi (gün) & 8,8 & 35,4 \\
\hline Yatak kullanım oranı (\%) & 69,4 & 72,6 \\
\hline Yatak devir hızı (hasta) & 29 & 7,5 \\
\hline FTR. Fiziksel Tıp ve Rehabilitasyon & &
\end{tabular}

FTR: Fiziksel Tip ve Rehabilitasyon

Tablo 2. Birinci dağıtım Fiziksel Tıp ve Rehabilitasyon kliniği maliyetleri.

\begin{tabular}{|l|c|c|}
\hline Maliyet Türü & Tutar (TL) & $\%$ \\
\hline Personel maaş & $2.147 .438,29$ & 39,49 \\
\hline Personel döner sermaye & $1.750 .909,27$ & 32,20 \\
\hline Illaç ve tıbbi malzeme & $261.442,28$ & 4,81 \\
\hline Beslenme & $360.719,88$ & 6,63 \\
\hline Temizlik & $342.677,21$ & 6,30 \\
\hline Elektrik, su, doğalgaz & $319.770,38$ & 5,88 \\
\hline Diğer & $254.749,57$ & 4,68 \\
\hline TOPLAM & $5.437 .706,88$ & 100,00 \\
\hline
\end{tabular}

ve 1.301.493,63 TL'sinin poliklinik maliyet yerine ait olduğu tespit edilmiştir. Maliyet merkezleri ve dağıtım aşamalarına göre maliyetler Tablo 3'de gösterilmiştir.

Bu aşamadan sonra, maliyet merkezlerinde toplanan hizmet maliyetleri, poliklinik sayısı, yatan hasta sayısı, hasta günü sayısı ve seans sayısı ile ilişkilendirilerek birim maliyetler hesaplanmış ve maliyet fonksiyonları oluşturulmuştur.

\section{FTR Kliniği Birim Maliyetleri}

Üçüncü dağıtım sonucunda maliyet merkezlerinde toplanan maliyetler, bu birimlerde üretilen hizmet miktarına bölünerek birim maliyetler hesaplanmıştır. Araştırmanın yürütüldüğü FTR kliniğinin 2010 yılına ait hizmet verileri ve birim maliyetleri Tablo 4'te görülmektedir. Buna göre 2010 yılında 18.070 poliklinik muayenesi, 576 hastaya yataklı tedavi ve bu hastalara 20.391 hasta günü hizmeti ile 26.724 seans FTR hizmeti verilmiştir. Bu verilerden hareketle, poliklinik birim maliyeti $72,02 \mathrm{TL}$, yatan hasta birim maliyeti 7.825,54 TL, yatan hastanın hasta günü maliyeti 221,05 TL ve FTR tedavisi seans maliyeti 49,38 TL olarak hesaplanmıştır.

\section{FTR Kliniği Maliyet Fonksiyonları}

Çalışmanın bu aşamasında toplam ve birim maliyet fonksiyonları oluşturulmuştur. Bu fonksiyonların oluşturulmasında; çalışanlara maaş olarak yapılan ödemeler sabit maliyet, ilaç ve tıbbi malzeme maliyetleri değişken maliyet, bunların dışındaki maliyetler ise yarı sabit - yarı değişken maliyet olarak değerlendirilmiştir. FTR Anabilim Dalı maliyetlerinin sabit ve değişken olarak dağılımı Tablo 5'te görülmektedir. Toplam maliyetlerin \%63,23'ü sabit, \%36,77'si değişken maliyetlerden oluşmaktadır. Maliyetlerin önemli bir bölümünün sabit oluşu üretilen hizmetin miktarı ile bağlantılı olarak birim maliyetleri etkilemektedir. Çalışmanın bu aşamasında sabit ve değişken maliyetlerden yararlanılarak maliyet merkezlerine göre toplam ve birim maliyet fonksiyonları oluşturulmuştur.

\section{FTR Poliklinik Toplam ve Birim Maliyet Fonksiyonları}

$\mathrm{Bu}$ bölümde FTR polikliniğinin toplam ve birim maliyet fonksiyonları oluşturulmuştur. Yukarıda ifade edildiği gibi toplam maliyet fonksiyonu; $\mathrm{TM}=\mathrm{ax}+\mathrm{b}$ şeklindedir. $\mathrm{a}=$ Birim Değişken Maliyet, $\mathrm{X}=$ Üretim Miktarı, $\mathrm{b}=$ Toplam Sabit Maliyet

$\mathrm{Bu}$ fonksiyonda üretim miktarı yani " $\mathrm{X}$ " poliklinik sayısıdır. Fonksiyonun oluşturulması için birim değişken maliyeti yani "a" yı hesaplamak gerekmektedir. Bunun için toplam değişken maliyetin üretim miktarını temsil eden poliklinik sayısına bölünmesi gerekmektedir. Tablo 4'te görüldüğü gibi, poliklinik maliyet merkezinin toplam sabit maliyeti $779.723,67 \mathrm{TL}$ ve toplam değişken maliyeti de 521.769,96 TL'dir. Ayrıca toplam poliklinik sayısı da 18.070'dır (Tablo 3).

Tablo 3. Íkinci dağıtım aşamalarına göre maliyet dağılımları (TL).

\begin{tabular}{|l|c|c|c|}
\hline \multirow{2}{*}{ Maliyet Merkezi } & \multicolumn{3}{|c|}{ Dağıtım Aşamaları } \\
\hline & 1. Dağıtım & 2. Dağıtım & 3. Dağıtım \\
\hline Poliklinik & $565.896,58$ & $\mathbf{7 0 6 . 4 1 8 , 5 7}$ & $1.301 .493,63$ \\
\hline Klinik & $3.655 .756,83$ & $3.945 .065,30$ & $4.507 .513,31$ \\
\hline FTR ünitesi & $1.216 .053,47$ & $1.224 .587,45$ & $1.319 .582,82$ \\
\hline Toplam & $\mathbf{5 . 4 3 7 . 7 0 6 , 8 8}$ & $\mathbf{5 . 8 7 6 . 0 7 1 , 3 1}$ & $\mathbf{7 . 1 2 8 . 5 8 9 , 7 6}$ \\
\hline
\end{tabular}

FTR: Fiziksel Tıp ve Rehabilitasyon 
$\mathrm{Bu}$ verilerden yola çıkarak $\mathrm{a}=521.769,96: 18.070=28,87$ $\mathrm{TL} /$ poliklinik olarak hesaplanmıştır. Elde edilen rakamlar fonksiyonda yerine konulduğunda FTR poliklinik toplam maliyet fonksiyonu;

TM (Poliklinik) $=28.87 * X+779.723,67$ olarak bulunmuştur.

Fonksiyonda $\mathrm{X}$ poliklinik sayısıdır. Bu fonksiyon farklı poliklinik sayılarına göre poliklinik toplam maliyetinin ne kadar olacağı konusunda bilgi verir. Örneğin poliklinik sayısının 25.000 olduğunu varsayarsak, TM $=28,87 * 25.000+779.723,67=$ 804.752,54 TL olacaktır. Toplam maliyetler birim maliyetler ile birlikte değerlendirildiğinde anlamlı çıkarımlar yapmak mümkün olmaktadır. Bilindiği üzere, birim maliyet fonksiyonu da, $B M=a+$ b / X şeklinde kurulmaktadır. a = Birim Değişken Maliyet, $\mathrm{X}=$ Üretim Miktarı, b = Toplam Sabit Maliyet

Fonksiyonda yer alan " $a$ " yani birim değişken maliyet yukarıda 28,87 TL olarak hesaplanmıştı. Üretim miktarı poliklinik sayısı olup 18.070 'dir, "b"de toplam sabit maliyettir. Bu verileri yerine koyduğumuzda, FTR poliklinik birim maliyet fonksiyonu, BM (poliklinik $)=28,87+779.723,67$ : $X$ olarak bulunmuştur.

Fonksiyonda $\mathrm{X}$ poliklinik sayısıdır. Bu fonksiyon farklı poliklinik sayılarına göre poliklinik birim maliyetinin ne kadar olacağı konusunda bilgi verir. Örneğin poliklinik sayısının 25.000 olduğunu varsayarsak, BM = 28,87 + 779.723,67: $25.000=60.05$ TL olacaktır. Görüldüğü üzere, poliklinik sayısı 18.070 iken bir poliklinik maliyeti 72,02 TL iken poliklinik sayısı 25.000'ne çıktığında birim maliyet 60,05 TL'na düşmektedir. Bu rakamlar sabit maliyetlerin önemini ve verimliliğin birim maliyetlere etkisini göstermektedir.

\section{FTR Klinik Toplam ve Birim Maliyet Fonksiyonlar}

Bu bölümde klinikte yatan hasta ve hasta günü toplam ve birim maliyet fonksiyonları oluşturulmuştur. Yatan Hasta Toplam ve Birim Maliyet Fonksiyonu; TM (yatan hasta) $=a x+b^{\prime}$ dir

Tablo 4. Fiziksel Tıp ve Rehabilitasyon kliniğinin 2010 yılına ait hizmet verileri ve birim maliyetleri.

\begin{tabular}{|l|c|c|c|}
\hline Hizmet & Sayı & $\begin{array}{c}\text { 3. Dağıım } \\
\text { Toplamı (TL) }\end{array}$ & $\begin{array}{c}\text { Birim } \\
\text { Maliyet (TL) }\end{array}$ \\
\hline Poliklinik & 18.070 & $1.301 .493,63$ & 72,02 \\
\hline Yatan hasta & 576 & $4.507 .513,31$ & $7.825,54$ \\
\hline Hasta günü & 20.391 & $4.507 .513,31$ & 221.05 \\
\hline FTR seansı & 26.724 & $1.319 .582,82$ & 49,38 \\
\hline
\end{tabular}

FTR: Fiziksel Tip ve Rehabilitasyon

Tablo 5. Fiziksel Tıp ve Rehabilitasyon kliniği sabit ve değişken maliyetleri.

\begin{tabular}{|l|c|c|c|}
\hline Maliyet Merkezi & \multicolumn{3}{|c|}{ Maliyet Türü } \\
\hline & Sabit & Değişken & Toplam \\
\hline Poliklinik & $779.723,67$ & $521.769,96$ & $1.301 .493,63$ \\
\hline Klinik & $2.815 .201,79$ & $1.692 .311,51$ & $4.507 .513,31$ \\
\hline FTR ünitesi & $912.367,43$ & $407.215,40$ & $1.319 .582,82$ \\
\hline Toplam & $4.507 .292,89$ & $2.621 .296,87$ & $7.128 .589,76$ \\
\hline Oran (\%) & 63,23 & 36,77 & 100,00 \\
\hline
\end{tabular}

FTR: Fiziksel Tip ve Rehabilitasyon
Bu fonksiyonda üretim miktarı yani " $X$ " yatan hasta sayısıdır. Fonksiyonun oluşturulması için; birim değişken maliyeti yani "a" hesaplamak gerekmektedir. Bunun için toplam değişken maliyetin üretim miktarına $(X)$ yani yatan sayısına bölünmesi gereklidir. Tablo 4' te görüldüğü gibi, klinik maliyetlerinin; 2.815.201,79 TL'si sabit, 1.692.311,51 TL'si değişken maliyetlerden oluşmaktadır. Toplam yatan hasta sayısı 576'dır (Tablo 3). Bu veriler ile; $\mathrm{a}=1.692 .311,51: 576=2.938,04 \mathrm{TL} /$ yatan hasta olarak hesaplanmıştır. Elde edilen rakamlar fonksiyonda yerine konulduğunda yatan hasta toplam maliyet fonksiyonu, TM (yatan hasta $)=2.938,04 * X+2.815 .201,79$ olarak hesaplanmıştır. Fonksiyonda $X$ yatan hasta sayısıdır. Bu fonksiyon farklı yatan hasta sayılarına göre klinik toplam maliyetinin ne kadar olacağı konusunda bilgi verir. Örneğin yatan hasta sayısının 1.000 olduğunu varsayarsak, TM $=2.938,04 * 1.000+2.815 .201,79=$ 5.753.241,79 TL olacaktır. Yatan hasta toplam maliyetleri önemli olmakla birlikte hasta başına birim maliyetler ve hasta günü başına toplam ve birim maliyetler ile birlikte değerlendirildiğinde anlamlı yorumlar yapma imkanı bulunmaktadır. Bu nedenle öncelikle yatan hasta başına birim maliyet fonksiyonu, daha sonra hasta günü toplam ve birim maliyet fonksiyonları oluşturulmuştur. Bilindiği üzere, birim maliyet fonksiyonu, $B M=a+b / X$ şeklinde kurulmaktadır. Fonksiyonda yer alan birim değişken maliyet yani "a" yukarıda 2.938,04 TL olarak hesaplanmıştır. Üretim miktarı yatan hasta sayısı olup $576^{\prime}$ dır, "b" de toplam sabit maliyettir. Bu verileri yerine koyduğumuzda, yatan hasta birim maliyet fonksiyonu; BM (yatan hasta) = 2.938,04 +2.815.201,79: X olarak bulunmuştur. Fonksiyonda $X$ yatan hasta sayısıdır. Bu fonksiyon farklı yatan hasta sayılarına göre yatan hasta birim maliyetinin ne kadar olacağı konusunda bilgi verir. Örneğin yatan hasta sayısının 1.000 olduğunu varsayarsak, $\mathrm{BM}=2.938,04+2.815 .201,79$ : $1.000=5.753 .24$ TL olacaktır. Görüldüğü üzere, yatan hasta sayısı 576 iken yatan hasta biri maliyeti 7.825,54 TL iken yatan hasta sayısı 1000'e çıktığında birim maliyet 5.753,24 TL'ye düşmektedir. Bu rakamlar sabit maliyetlerin ve klinik verimliliğin önemini göstermektedir.

\section{Hasta Günü Toplam ve Birim Maliyet Fonksiyonu}

$\mathrm{TM}$ (hasta günü) $=\mathrm{ax}+\mathrm{b}$

$\mathrm{Bu}$ fonksiyonda üretim miktarı yani " $X$ " klinik hasta günü sayısıdır. Fonksiyonun oluşturulması için; birim değişken maliyeti yani "a" $y ı$ hesaplamak gerekmektedir. Bunun için toplam değişken maliyetin üretim miktarına $(X)$ yani klinik hasta günü sayısına bölünmesi yeterlidir. Tablo 4'te görüldüğü gibi, klinik maliyetlerinin 2.815.201,79 TL'si sabit, 1.692.311,51 TL'si değişken maliyetlerden oluşmaktadır. Ayrıca toplam yatan hasta gün sayısı da 20.391 'dir (Tablo 3). Bu veriler ile, $a=1.692 .311,51$ : $20.391=82,99 \mathrm{TL} /$ hasta günü olarak hesaplanır. Bu verileri fonksiyonda yerine koyduğumuzda yatan hasta günü toplam maliyet fonksiyonu; TM (hasta günü) $=82,99 * X+2.815 .201,79$ olarak hesaplanmıştır.

Fonksiyonda $X$ yatan hasta günü sayısıdır. Bu fonksiyon farklı yatan hasta günü sayılarına göre klinik toplam maliyetinin ne kadar olacağı konusunda bilgi verir. Örneğin yatan hasta günü sayısının 25.000 olduğunu varsayarsak, TM $=82.99 * 25.000+$ $2.815 .201,79=4.889 .951,79$ TL olacaktır. Hasta günü önemli bir 
klinik performans göstergesidir. Bu nedenle bir hasta gününün hastaneye maliyeti önem arz etmektedir. Birim maliyet fonksiyonu, $\mathrm{BM}=\mathrm{a}+\mathrm{b} / \mathrm{X}$ şeklinde kurulmaktadır. Fonksiyonda yer alan birim değişken maliyet yani "a" yukarıda 82,99 TL olarak hesaplanmıştır. Üretim miktarı yatan hasta gün sayısı olup 20.391 'dir, "b" de toplam sabit maliyettir. Bu verileri yerine koyduğumuzda, klinik hasta günü birim maliyet fonksiyonu; $B M$ (hasta günü) $=82,99$ +2.815.201,79: X olarak bulunmuştur.

Fonksiyonda $\mathrm{X}$ yatan hasta gün sayısıdır. Bu fonksiyon farklı yatan hasta gün sayılarına göre bir hasta gününün hastaneye maliyetinin ne kadar olacağı konusunda bilgi verir. Örneğin yatan hasta günü sayısının 25.000 olduğunu varsayarsak, $\mathrm{BM}=82,99+$ 2.815.201,79: $25.000=195,60$ TL olacaktır. Görüldüğü üzere, yatan hasta günü sayısı 20.391 iken yatan hasta günü birimi maliyeti 221,05 TL iken yatan hasta günü sayısı 25.000 'e çıktığında hasta günü birim maliyet 195,60 TL'ye düşmektedir. Bu rakamlar sabit maliyetlerin ve klinik verimliliğin önemini göstermektedir.

Fizik Tedavi ve Rehabilitasyon Ünitesi Toplam ve Birim Maliyet Fonksiyonları

$\mathrm{Bu}$ bölümde FTR ünitesinin toplam ve birim maliyet fonksiyonları oluşturulmuştur. FTR ünitesinde hastalara farklı fizik tedavi ve rehabilitasyon yöntemleri uygulanmaktadır. Bu uygulama yöntemlerine ilişkin ayrıntılı veri elde edilemediği için eşit olarak değerlendirilmişlerdir. Toplam maliyet fonksiyonu; $\mathrm{TM}=\mathrm{ax}+\mathrm{b}$ şeklindedir. Bu fonksiyonda, $\mathrm{a}=$ Birim Değişken Maliyet, $\mathrm{X}=$ Üretim Miktarı, $\mathrm{b}=$ Toplam Sabit Maliyet

$\mathrm{Bu}$ fonksiyonda üretim miktarı yani " $X$ " fizik tedavi seans sayısıdır. Fonksiyonun oluşturulması için; birim değişken maliyeti yani "a" maliyetin üretim miktarına $(X)$ yani FTR seans sayısına bölünmesi gerekmektedir. Tablo 4'te görüldüğü gibi, FTR ünitesi maliyet merkezinin toplam sabit maliyeti $912.367,43$ TL ve toplam değişken maliyeti de 407.215,40 TL'dir. Toplam seans sayısı 26.724'tür (Tablo 3). Bu veriler ile, $a=407.215,40$ : $26.724=$ $15,24 \mathrm{TL} /$ seans olarak hesaplanmıştır. Bu verileri fonksiyonda yerine koyduğumuzda FTR ünitesi merkezi toplam maliyet fonksiyonu; TM (FTR ünitesi) $=15,24 * X+912.367,43$ olarak bulunmuştur.

Fonksiyonda X FTR seans sayısıdır. Bu fonksiyon farklı FTR seans sayılarına göre ünitenin toplam maliyetinin ne kadar olacağı konusunda bilgi verir. Örneğin FTR seans sayısının 35.000 olduğunu varsayarsak, $\mathrm{TM}=15.24 * 35.000+912.367,43=$ 1.445.763,43 TL olacaktır. Toplam maliyetler birim maliyetler ile birlikte değerlendirildiğinde anlamlı yorumlar yapma imkânı bulunmaktadır. Birim maliyet fonksiyonu; $B M=a+b / X$ şeklinde kurulmaktadır. $\quad \mathrm{a}=$ Birim Değişken Maliyet, $\mathrm{X}=$ Üretim Miktarı, b = Toplam Sabit Maliyet

Fonksiyonda yer alan birim değişken maliyet yani "a" yukarıda 15,24 TL olarak hesaplanmıştı. Üretim miktarı fizik tedavi seans sayısı olup 26.724 'tür, "b"de toplam sabit maliyettir. Bu verileri yerine koyduğumuzda, FTR ünitesi birim maliyet fonksiyonunu, BM (FTR ünitesi) $=15,24+912.367,43:$ X olarak bulunmuştur.

Fonksiyonda X FTR seans sayısıdır. Bu fonksiyon farklı FTR seans sayılarına göre ünitenin birim maliyetinin ne kadar olacağı konusunda bilgi verir. Örneğin FTR seans sayısının 35.000 olduğunu varsayarsak, $\mathrm{BM}=15,24+912.367,43: 35.000=41,30$
TL olacaktır. Görüldüğü üzere seans sayısı 26.724 iken bir seansın maliyeti, 49,38 TL olurken seans sayısı 35.000'ne çıktığında seans birim maliyet 41,30 TL'ne düşmektedir. Bu rakamlar sabit maliyetlerin önemini ve verimliliğin birim maliyetlere etkisini göstermektedir.

\section{Tartışma}

Sosyal Güvenlik Kurumu, hastaneler ve Türk Tabipleri Birliği gibi meslek örgütleri maliyet çalışmaları yapmadan fiyatlandırma kuralları oluşturmaktadır. Maliyet analizi yapılmaması hizmet fiyatlarının olduğundan yüksek ya da düşük belirlenmesine yol açmaktadır. Bu durum hastanelerin ya da geri ödeme kurumlarının zarar etmesine yol açmaktır. Ayrıca ücretli ödemeleri ve yasal olmayan ödemeleri arttırıcı etkisi de olabilmektedir. Özellikle hastaneler, geri ödeme kurumlarının tek taraflı olarak belirlediği fiyatların çok düşük olduğunu ve bu nedenle maliyetlerinin altında hizmet verdiklerini ve zarar ettiklerini ileri sürmektedirler. Ancak hastanelerin bu savlarını belgeleyen kanıtları bulunmamaktadır. Çünkü sınılı sayıdaki yüksek lisans ve doktora tezleri dışında hastanelerde sistematik olarak ayrıntılı maliyet analizi çalışmaları yapılmamaktadır. Bu nedenle bu söylemler geri ödeme kurumlarının kararlarına etki etmemektedir. Mevcut çalışmanın bu sürece olumlu katkı yapacağı düşünülmektedir. Yapılmış benzer bir çalışma bulunamadığından çalışmanın bulguları; SGK Sağlık Uygulama Tebliği 2010 yılı fiyatları ile karşılaştırarak yorumlanmıştır.

Çalışmanın yürütüldüğü Fiziksel Tıp ve Rehabilitasyon Kliniğinde, personel maliyetlerinin toplam maliyetler içindeki oranı oldukça yüksek bulunmuştur $(\% 71,69)$. İlaç ve tıbbi malzeme maliyetlerinin toplam maliyetler içindeki oranı $\% 4,81$ ve genel üretim maliyetlerinin toplam maliyetler içindeki oranı $\% 23,5$ olarak hesaplanmıştır. Bu maliyet yapısı FTR kliniğinde sunulan hizmetlerin özelliği ve ekip yaklaşımı ile açıklanabilir. Kardiyovasküler Cerrrahi Kliniğinde yapılan bir çalışmada, personel maliyetlerinin oranı $\% 47,6$, ilaç ve tıbbi malzeme maliyetlerinin oranı \%32,3 ve genel üretim maliyetlerinin oranı \%20,1 olarak bulunmuştur (9). Özel bir üremeye yardımcı tedavi merkezinde yapılan araştırmada, personel maliyetlerinin oranı $\% 46,3$, ilaç ve tıbbi malzeme maliyetlerinin oranı $\% 29,5$, genel üretim maliyetlerinin oranı \%24,2 olarak bulunmuştur (10). Sonsuz (11), özel bir hastanede personel maliyetleri oranını \%31,5, ilaç ve tıbbi malzeme maliyetleri oranını $\% 35,7$, genel üretim maliyetlerinin oranını \%32,8 olarak bulmuştur. Yiğit ve Ağırbaş (12) tarafından, Sağlık Bakanlığı Tokat Doğum ve Çocuk Bakımevi Hastanesi'nde yürütülen araştıma sonucunda, toplam maliyetlerin \%58'ini personel maliyetleri, \%16,4'ünü ilaç ve tıbbi malzeme maliyetleri, \%25,6'sını ise genel üretim maliyetleri oluşturmuştur. Görüldüğü gibi, diğer bölümlerle kıyaslandığında FTR kliniğinde sunulan hizmetler emek ağırıılıdır. Bu özellik fizik tedavi ve rehabilitasyon maliyetlerini etkilemektedir. Geri ödeme kurumları tarafından ödeme esasları belirlenirken bu özelliğin dikkate alınmasında yarar bulunmaktadır.

Sosyal Güvenlik Kurumu SUT'ta, araştırmanın yürütüldüğü hastane için 2010 yılı FTR ayaktan hasta muayene paket ücreti 55 TL olarak belirlenmiştir. Çalışmada FTR poliklinik muayene maliyeti 
72,02 TL bulunmuştur. Bu durumda gerçek maliyetin paket fiyattan yaklaşık \%31 daha fazla olduğu görülmektedir. Sosyal Güvenlik Kurumu SUT'ta gündelik standart yatak ücreti; yemek, yatak ve hasta vizit ücreti dahil 30 TL olarak belirlenmiştir. Çalışmada hasta günü maliyeti 221,05 TL olarak hesaplanmıştır. Çalışmanın kapsadığı maliyetler daha geniş kapsamlı olduğu için rakamın belirli oranda yüksek olması normal karşılanabilir. Bu durum iki rakam arasındaki yaklaşık yedi katlık farkı açıklamak için yeterli değildir. Bu fark önemli oranda SGK tarafından belirlenen rakamın düşüklüğünden kaynaklanmaktadır. SGK tarafından belirlenen rakamın düşük olması ve bu rakamın bütün klinikler için aynı olması FTR gibi hastaların zorunlu olarak uzun süre yatması gereken klinikleri olumsuz olarak etkilemekte ve bu klinikler için dezavantajı bir durum yaratmaktadır. Bunun bir sonucu olarak yatan hasta ücretleri ve maliyetleri de oldukça farklı olmaktadır. Araştırmanın yürütüldüğü FTR kliniğinde ortalama yatış süresi 35,4 gündür. Bu rakam gündelik yatak ücreti olan $30 \mathrm{TL}$ ile çarpıldığında bir yatan hastanın maliyeti 1.062 TL olarak bulunmaktadır. Bu rakama diğer maliyet unsurları da eklendiğinde yaklaşık 1.500 TL olacağı düşünülmektedir. Oysa çalışmada yatan hasta maliyetinin 7.825,54 TL olduğu görülmektedir.

Araştırmanın yürütüldüğü hastanenin FTR ünitesinde hastalara farklı yöntemler uygulanmaktadır. Bu uygulama yöntemlerine ilişkin ayrıntılı veri elde edilemediği için eşit olarak değerlendirilmiş ve fizik tedavi seans maliyeti 49,38 TL olarak hesaplanmıştır. SGK SUT eki, EK-8'de yer alan hizmet başı ödeme usulüne göre FTR seans maliyetleri 1,80 TL ile $30 \mathrm{TL}$ arasında değişmektedir. Bu fiyatların gerçek maliyetin çok altında olduğu görülmektedir. Diğer yandan SGK 2010 yılından itibaren, ayaktan ve yatarak tedavi gören hastalara uygulanacak FTR uygulamalarını, SUT eki EK-9/A da yer alan tanı gruplarını dikkate almak suretiyle geri ödemeye başlamıştır. Buna göre A grubunda yer alan tanılar için $80 \mathrm{TL}, \mathrm{B}$ grubunda yer alan tanılar için $60 \mathrm{TL}, \mathrm{C}$ grubunda yer alan tanılar için $30 \mathrm{TL}$ ve D grubunda yer alan tanılar için 20 TL ödemektedir. Ancak FTR kliniğinde tedavi gören hastalar büyük oranda D grubuna girmekte ve bu hastalar için günlük $20 \mathrm{TL}$ geri ödeme yapılmaktadır. Bu tutar gerçek maliyetin \%40,5'ini karşılayabilmektedir. Bu nedenle tedavi ünitesinde uygulanan FTR uygulamalarının özellikleri ayrıntılı olarak dikkate alınarak faaliyet tabanlı bir maliyet çalışması yapılmasında yarar bulunmaktadır.

\section{Öneriler}

- Maliyet analizi yöneticilerin sağlıklı karar vermelerine yardımcı olan önemli bir finansal yönetim aracıdır. Bu aracın kullanılabilmesi için hastanelerde maliyet muhasebesi sistemi kurulmalıdır. Düzenli olarak maliyet analizleri yapılmalı ve analiz sonuçları yönetsel kararlarda kullanılmalıdır. Bazı özellikli birimler için faaliyet tabanlı maliyetleme çalışmaları yapılmadır.

- Araştırmanın yürütüldüğü FTR kliniğinde olduğu gibi hastane maliyetleri içinde sabit maliyetler ağırıklı olup toplam maliyetler içinde personel maliyetleri önemli bir yer tutmaktadır. Bu maliyet yapısı mevcut kaynakların verimli olarak kullanılmasının ne kadar gerekli olduğunu göstermektedir. Personel başta olmak üzere verimliliği arttırıcı uygulamaların katılımcı bir yaklaşım ile geliştirilmesi yararlı olacaktır.

- Sosyal Güvenlik Kurumu SUT'ta bütün klinikler için tek ve sabit bir gündelik yatak ücreti belirlenmiştir. Bu ödeme sistemi FTR gibi hastalarını zorunlu olarak uzun süre yatırmaları gereken klinikleri olumsuz olarak etkilemektedir. Bu klinikler hastalarını uzun süre yatırdıkları için yatak devir hızları düşük olmaktadır. Bu da maliyetlerinin yükselmesine ve gelirlerinin azalmasına yol açmaktadır. Bilindiği üzere Türkiye'de Sağlık Bakanlığı ve kamu üniversite hastanelerinde; döner sermaye gelirlerinden performansa dayalı olarak çalışanlara ek ödeme yapılmaktadır. Bu ödeme sistemi nedeniyle FTR çalışanları oldukça dezavantajı bir konumda kalmaktadır. Söz konusu dezavantajların ortadan kaldırılması için maliyet analizi çalışmaları yapılmalı ve bu analizlerin sonuçları dikkate alınarak bu tür klinikler için farklı gündelik yatak ücreti belirlenmelidir.

- Fiziksel Tıp ve Rehabilitasyon, tıbbi tedavinin yanında hastaların işlevselliği ve yaşam kalitesi ile doğrudan ilgilenen bir uzmanlık alanıdır. FTR uzmanlarının hastaların yaşam kalitesi ve sağlığından ödün vermeden klinik yatış sürelerini kısaltarak yatak devir hızını arttırıcı uygulamalar üzerinde çalışmalar yapmalarının yararlı olacağı söylenebilir.

- Maliyet analizi çalışmalarının bütün hastaneler tarafından yapılarak SGK ile yapılan görüşmelerde kullanılmasında yarar bulunmaktadır. Böylece tıp fakültesi hastaneleri ile eğitim ve araştırma hastanelerinin maliyetlerinin yüksek olduğu ortaya konularak farklı hizmet ücret politikası talep etmenin kanıtları olacaktır. Farklı hizmet ücret politikası ile tıp fakültesi hastaneleri ile eğitim ve araştırma hastanelerinin finansal sürdürülebilirlikleri üzerindeki tehdit ortadan kalkacaktır.

\section{Çıkar Çatışması:}

Yazarlar herhangi bir çıkar çatışması bildirmemişlerdir.

\section{Kaynaklar}

1. Menderes M. Hastanelerde Maliyet Hesaplaması ve Hemşirelik Hizmetleri Maliyetleri. Hacettepe Üniversitesi Hemşirelik Yüksekokulu Dergisi 1994;1:65-70.

2. Akar C. Hastane Issletmelerinde Yönetim Muhasebesi (Doktora Tezi). Sosyal Bilimler Enstitüsü: Gazi Üniversitesi; 1992.

3. Menderes M. Hastanelerde Muhasebe, Maliyetleme Sorunları ve Finansal Yönetim. Toplum ve Hekim 1995;10:32-46.

4. Ildır A. Faaliyet Tabanlı Maliyetleme Ile Sağlık Isşletmelerinde Maliyet Analizi ve Performans Yönetimi. Ankara: Seçkin Yayınclık; 2008. s:18.

5. Şahin I. Hastanelerde Birim Çıktı maliyetlerinin Analizi ve Kapasite Kullanım Faktörünün Maliyetlere Etkisi: Sağlık Bakanlığı Zübeyde Hanım Doğum Evinde Bir Uygulama (Yüksek Lisans Tezi). Sağlık Bilimleri Enstitüsü: Hacettepe Üniversitesi; 1992.

6. Shepard DS, Hodgkin D, Anthony YE. Analysis of Hospitals Costs: A Manuel For Managers. Genova: World Health Organization Report; 2000.

7. Akar Ç, Şahin I, Ergin G. ve ark. Hacettepe Üniversitesi Sağlık Hizmetleri Finansman Yapısının Güçlendirilmesi ve Yeniden Yapılandırılması İçin Altyapı Geliștirilmesi Projesi, DRG Maliyetlendirme Rehberi-2 (Versiyon 1). Hastane Gider Yerleri Hesap Planı ve Veri Kaynakları Analizi, Ankara; 2006.

8. Esatoğlu AE, Ağırbas I, Payziner PD, Akbulut Y, Göktas B, Özatkan $Y$, ve ark. Ankara Üniversitesi Tıp Fakültesi Hastaneleri'nde Maliyet Analizi. Ankara Üniversitesi Tıp Fakültesi Mecmuası 2010;61:17-27.

9. Erkol Ü. Hastanelerde Maliyet Analizi ve Faaliyet Tabanlı Maliyetleme Yöntemine Dayalı Bir Uygulama (Tezsiz Yüksek Lisans Dönem Projesi), Ankara Üniversitesi Sağlık Bilimleri Enstitüsü: Ankara Üniversitesi; 2010.

10. Baykal B. Üremeye Yardımcı Tedavi Uygulamalarında Maliyet Analizi: Özel Bir ÜYTE Merkezinde Bir Araștırma (Yüksek Lisans Tezi). Sağlık Bilimleri Enstitüsü: Hacettepe Üniversitesi; 2010.

11. Sonsuz AA. Hastane Isşletmelerinde Birim Maliyetlerin Analizi: Bir Özel Hastane Örneği (Yüksek Lisans Tezi). Sağlık Bilimleri Enstitüsü: Ankara Üniversitesi; 2011.

12. Yiğit V, Ağırbas I. Hastane İsletmelerinde Kapasite Kullanım Oranının Maliyetlere Etkisi: Sağılık Bakanlığı Tokat Doğum ve Çocuk Bakımevi Hastanesi'nde Bir Uygulama. Hacettepe Sağlık Idaresi Dergisi 2004;2: 141-162. 